\title{
O PAPEL ÉTICO-POLÍTICO DA EDUCAÇ̃̃O NA SUPERAÇÃO DA CRISE SOCIOAMBIENTAL: UMA ANÁLISE GRAMSCIANA.
}

\author{
Luciane Albernaz de AraujoFREITAS ${ }^{1}$ \\ André Luis Castro de FREITAS ${ }^{2}$
}

RESUMO:A crise socioambiental atinge proporções alarmantes, devendo ser pensada para além do meio físico e biológico. Esta se configura como um problema que abrange as dimensões: econômica, social, políticas, em suas inter-relações, estando diretamente condicionada ao modelo civilizatório vigente, o capitalismo. Tendo como suporte teórico o pensamento marxiano e os pressupostos da Educação Ambiental Transformadora, este artigo objetiva problematizar o papel da educação na superação da crise socioambiental para a construção de uma educação e, sobretudo, de uma prática pedagógica que esteja em sintonia com os anseios de contribuir com o processo contrahegemônico. Nessa perspectiva, problematiza-se o pensamento gramsciano, sobretudo do papel ético-político da educação para a superação da crise socioambiental.

PALAVRAS-CHAVE:Crise socioambiental. Educação ambiental transformadora. Pensamento marxiano.

\section{INTRODUÇÃO}

[...] Todas as coisas estão ligadas como o sangue que une uma família. Há uma ligação em tudo. O que ocorre com a terra recairá sobe os filhos da terra. O homem não tramou o tecido da vida; ele é, simplesmente, um de seus fios. Tudo o que fizer ao tecido, fará a si mesmo [...] (Carta do Cacique Seattle)

"O mundo vivência uma crise socioambiental sem precedentes". "A crise socioambiental é alarmante”. Estas são afirmações correntes entre estudiosos das mais diversas áreas do conhecimento e estão cotidianamente sendo proclamadas. Ir contra essas afirmações torna-se um desejo que, no presente momento não pode ser realizado. A situação é preocupante, mas é preciso enfrentá-la: o mundo vive uma grande crise que segundo Leff $(2000$, p.41) “[...] não só se manifesta na destruição do meio físico e biológico, mas também na degradação da qualidade de vida, tanto no âmbito rural como no urbano."

${ }^{1}$ Doutora em Educação Ambiental.UFRS - Universidade Federal do Rio Grande - Pós-graduação em Educação Ambiental. Rio Grande - RS - Brasil. 96203-900. Instituto Federal de Educação, Ciência e Tecnologia Sul-Rio-Grandense. Pelotas - RS - Brasil. 96015-360 -lucianealbernaz@ pelotas.ifsul.edu.br

${ }^{2}$ Doutorando em Educação.UFPEL - Universidade Federal de Pelotas - Pós-graduação em Educação. Pelotas - RS - Brasil. 96010-610.UFRS - Universidade Federal do Rio Grande. Rio Grande - RS - Brasil. 96203-900 -dmtalcf@furg.br 
A epígrafe que inicia este artigo ao expressar que "[...] Todas as coisas estão ligadas como o sangue que une uma família. Há uma ligação em tudo. O que ocorre com a terra recairá sobe os filhos da terra. [...]" vem ao encontro da concepção que permeará este trabalho, o qual compreende a crise ambiental para além do ambiente físico, abrangendo necessariamente as dimensões: econômica, social, políticas, em suas inter-relações. Ainda em sintonia com a epígrafe que afirma que: “[ [... O homem não tramou o tecido da vida; ele é, simplesmente, um de seus fios. Tudo o que fizer ao tecido, fará a si mesmo [...]" acredita-se que a crise socioambiental esteja diretamente condicionada ao modelo civilizatório vigente, o capitalismo. Assim tendo como suporte teórico o pensamento de Marx e Gramsci, tem-se como objetivo neste artigo problematizar o papel ético-político da educação na superação da crise socioambiental.

Nesta perspectiva lançar-se-á mão dos fundamentos da Educação Ambiental Transformadora, a qual investe na necessidade de uma transformação social, sendo necessário, para tanto, mudanças profundas e radicais no modelo de sociedade em vigor a fim de eliminar os mecanismos responsáveis pela desigualdade e injustiça, como é o caso da exploração econômica, concentração de renda entre tantos outros fatores que acompanham os processos de apropriação privada dos bens materiais. Para tal inicia-se pelo tópico intitulado de $A$ crise socioambiental: uma crise civilizatória, este intenta desvelar a amplitude e profundidade da crise socioambiental, a qual está para além do mau uso dos recursos naturais, constituindo-se numa crise do modelo civilizatório. $\mathrm{Na}$ sequência tem-se o tópico A superação do capitalismo: conhecer para transformar, este aborda a Educação Ambiental Transformadora como um balizador para a construção de uma educação e, sobretudo, de uma prática pedagógica que esteja em sintonia com os anseios de contribuir com o processo contra- hegemônico, nessa perspectiva lança-se mão do pensamento gramsciano, sobretudo do papel ético-político da educação para a superação da crise socioambiental.

\section{A CRISE SOCIOAMBIENTAL: UMA CRISE CIVILIZATÓRIA}

Os problemas socioambientais enfrentados pela sociedade contemporânea não se limitam a questões referentes ao meio-ambiente. Não se trata somente de problema de caráter cultural e comportamental, mas sim de uma crise civilizatória e porque não dizer de destino. Esta crise está atrelada a lógica do modelo civilizatório em curso, isto é a lógica de produção capitalista. Desta forma, pensar na superação da crise socioambiental é pensar para além de mudanças de caráter apenas conjuntural, pois 
essas não abalam os mecanismos de reprodução social mantendo inalteradas as relações de poder. Faz-se necessário pensar em mudanças profundas e radicais, isto é, na construção de outro modelo societário a fim de eliminar os mecanismos responsáveis pelas desigualdades e injustiças, como é o caso da exploração econômica, concentração de renda entre tantos outros fatores que acompanham os processos de apropriação privada dos bens materiais.

O entendimento da amplitude e complexidade da crise socioambiental é fator determinante para que se possa refletir acerca das possibilidades de sua superação. Nesse intuito torna-se indispensável qualificar a reflexão acerca do modo de produção capitalista como determinante não só das necessidades físicas dos indivíduos, mas da vida em todas as suas dimensões.

A compreensão desse posicionamento encontra sustentação no marxismo originário.Marx constrói seu pensamento com base no diálogo com a filosofia alemã, de modo especial com Hegel -, e a economia política inglesa - sobretudo com Adam Smith e David Ricardo -, ao estabelecer as limitações de cada corrente de pensamento avança na elaboração de seu método.

Marx e Engels dedicam-se na construção de uma crítica da filosofia póshegeliana, onde intentavam explicitar que suas formulações tratavam de um avanço em relação às formulações idealistas de Hegel e, também, ás formulações materialistas de Feuerbach.

Com o propósito de ultrapassar os limites das concepções hegeliana e feuerbachiana Marx e Engels se debruçam sob o problema fundamental da filosofia: a determinação do real e a determinação da existência social do homem. Em A Ideologia Alem $\tilde{a}^{3}$ os dois filósofos ampliam e aprofundam as críticas feitas, em escritos anteriores, aos hegelianos de esquerda ${ }^{4}$, acusando-os de limitarem-se ao confronto com o sistema hegeliano no reino do pensamento abstrato, sem levar em conta a difícil situação real alemã.

[...] Os jovens ideólogos são, apesar de suas frases feitas pretensamente "abaladoras do mundo", os maiores conservadores. [...]

\footnotetext{
${ }^{3}$ Esta obra escrita entre os anos de 1845 e 1846 e publicada somente em 1932, pode ser considerada o ponto de partida da exposição do percurso metodológico de Marx, pois nela Marx e Engels explicitam pela primeira vez as bases sob as quais formulam seu método em oposição ao idealismo hegeliano. "A ideologia alemã marca, portanto, o nascimento do materialismo histórico" (BACKES, 2007, p.11).

${ }^{4}$ Conhecidos também como "jovens hegelianos" ou "neo-hegelianos", eram um grupo de jovens professores e estudantes que defendiam mudanças na sociedade da Prússia, opondo-se as tendências conservadoras dos "hegelianos de direita" (BACKES, 2007, p.9).
} 
A nenhum desses filósofos ocorreu à ideia de perguntar acerca da relação existente entre a filosofia alemã e a realidade alemã, da relação da crítica que fazem com seu próprio ambiente natural. (MARX; ENGELS, 2007, p.41).

A oposição a primazia do pensamento da concepção idealista hegeliana faz Marx e Engels explicitarem seus pressupostos, os quais não são formulações vazias de um pensamento que parte do nada e ao nada retorna. São pressupostos reais originados da realidade concreta e não uma produção das ideias. Nesta perspectiva, apontam como primeiro pressuposto da história humana “[...] a existência de indivíduos humanos vivos" (MARX; ENGELS, 2007, p.41).

Assim, o primeiro elemento a ser considerado na historiografia humana é "[...] a organização corporal desses indivíduos e sua relação com o restante da natureza, resultante desta mesma organização.” (MARX; ENGELS, 2007, p.42). Tem-se a partir desta lógica a satisfação das necessidades básicas como preocupação primeira do ser humano, as quais têm de ser renovadas a cada dia, pois para fazer história é preciso estar vivo e para tal "[...] fazem falta antes de tudo comida, bebida, moradia, vestimenta e algumas coisas mais." (MARX; ENGELS, 2007, p.50), remetendo à necessidade primeira a produção da vida material.

Entretanto esse modo de produção da vida material não se limita a reprodução das necessidades físicas dos indivíduos, mas acaba por determinar uma forma de vida em todas as suas dimensões. “O que os indivíduos são, portanto, depende das condições materiais de sua produção." (MARX; ENGELS, 2007, p.42).

Esta tese é ratificada por Marx e Engels (2007) ao abordarem o desenvolvimento da propriedade em suas diferentes formas: tribal, estatal ou comunitária e feudal ou estamental. Ao relacionar cada uma destas formas com um estágio de desenvolvimento da divisão do trabalho, explicitam que a forma de produção de cada sociedade estabelece as relações sociais e políticas destas. A este respeito Marx e Engels (2007, p.47-48) afirmam:

[...] determinados indivíduos, que são ativos na produção de determinada maneira, contraem entre si essas determinadas relações sociais e políticas. [...] A estrutura social e o Estado brotam constantemente do processo de vida de determinados indivíduos; mas esses indivíduos tomados não conforme possam se apresentar ante a imaginação própria ou alheia, mas sim como realmente são, quer dizer, como atuam, como produzem materialmente e, portanto, tal 
como desenvolvem suas atividades sob determinados limites, premissas e condições materiais, independentes de seu arbítrio.

A produção da vida material, no entanto encontra-se condicionada as determinações da natureza e aquelas que devem ser produzidas que, por sua vez atrelam-se as condições materiais determinadas pela forma de produção. Pode-se então afirmar que a forma de produção acaba por estabelecer as relações entre os homens no processo, bem como as demais relações humanas. Neste sentido, a proposta marxiana defende que o modo de produção da vida material condiciona o processo da vida social, política e espiritual em geral. Não é a consciência do homem que determina o seu ser, mas, pelo contrário, o seu ser social é que determina sua consciência. Tem-se, então a necessidade de refletir sobre o problema ambiental de forma articulada com a totalidade das dimensões da sociedade, pois a não articulação tem como resultado uma visão dualista de mundo onde "[...] a luta pela proteção da natureza sobressai como algo hierarquicamente prioritário sobre a luta por justiça e igualdade social, em vez de serem percebidas como intrinsecamente vinculadas.” (LAYRARGUES, 2006, p.14). Tal compreensão leva a crer que a superação da crise socioambiental está condicionada a superação do modo de produção capitalista.

\section{A SUPERAÇÃO DO CAPITALISMO: CONHECER PARA TRANSFORMAR}

Ao compreenderavinculação das bases ecológicas com a esfera material, vinculadas ao modo de produção capitalista e as relações sociais em sua concretude, percebe-se que o caminho em busca da superação da crise socioambiental é apostar na construção de em um novo modelo societário.

Para Layrargues (2006) é premente a construção de uma sociedade ecologicamente criteriosa e responsável e, ainda, socialmente justa tendo a dialética como estratégia de mediação entre mudança social e mudança cultural. Porém esse mesmo autor enfatiza que a mudança só se faz possível quando se leva em consideração a sociedade da qual se é parte, pois os valores são “[...] definidos a partir de condições históricas específicas, inseridas num mundo dialético de mútua constituição entre objetividade e subjetividade.” (LAYRARGUES, 2006, p.13).

Nessa perspectiva acredita-se no importante papel da Educação Ambiental Transformadora (EAT) que, partindo de uma situação concreta: o esgotamento das condições matérias do planeta e suas decorrências, tendo como base ontológica e 
gnosiológica, o materialismo histórico dialético, impulsionam o entendimento da “[...] educação não como o único meio para a transformação, mas como um dos meios sem o qual não há mudança.” (LOUREIRO, 2006, p.58). Para tanto se faz necessidade de refletir sobre o problema ambiental de forma articulada com a totalidade das dimensões da sociedade, pois a não articulação resulta em uma visão dualista de mundo, onde “[...] a luta pela proteção da natureza sobressai como algo hierarquicamente prioritário sobre a luta por justiça e igualdade social, em vez de serem percebidas como intrinsecamente vinculadas." (LAYRARGUES, 2006, p.14).

Compreender a EAT em sua amplitude e complexidade permite fazer, de seus pressupostos balizadores a construção de uma educação e, sobretudo, de uma prática pedagógica que esteja em sintonia com os anseios de contribuir com o processo contrahegemônico. Nesse sentido, deve-se ter presente que a:

Educação Ambiental crítica, transformadora, socioambiental e popular refere-se, enquanto práxis social e processo de reflexão sobre a vida e a natureza, contribuindo com a transformação do modo como nos inserimos e existimos no mundo, a uma única categoria teórico-prática estruturante: educação. (LOUREIRO, 2006, p.35).

Partindo desse entendimento buscam-se no pensamento de Antônio Gramsci subsídios para a reflexão acerca do papel da educação no processo contra-hegemônico. Esse autor fundamenta sua prática, ético-política a partir de análises das transformações processadas no mundo no qual estava inserido. Essa análise permite perceber que as modificações na produção material não têm fim em si mesmo. Na passagem do século XIX para o século XX foram vivenciadas mudanças significativas nas relações materiais de produção, as quais levaram a consolidação da hegemonia burguesa determinando as relações sociais, tem-se assim a constituição do bloco histórico capitalista.

Movido pela vontade de ver superado o bloco histórico capitalista Gramsci dedica-se a analisar, em sua concretude, as causas que levaram a revolução socialista na Itália ao fracasso, tendo como meta compreender as imbricações e articulações envolvidas na situação estrutural e superestrutural com o intuito de formular estratégias capazes de modificá-la a favor das classes subalternas. A partir desta perspectiva o pensador sardo entrega-se a um processo de teorização, com vistas à construção de alternativas revolucionárias. Este estudo lhe permite compreender que a realidade ganhou novos contornos a partir do final do século XIX, passando a organizar-se a 
partir de um conjunto de dimensões - política, social, cultural - não podendo ser pensada unicamente como decorrente das relações de produção.

Ao compreender a complexidade que envolve a organização da realidade concreta, tendo como pressuposto a influência das dimensões social, cultural, política e as alterações nas relações entre as classes sociais ocasionadas por tal influência, Gramsci têm seu campo de análise ampliado em relação às análises realizadas por Marx e Engels. A esfera do político perde sua magnitude, para ser percebida como parte de uma organização maior que traz em seu bojo também, as forças ideológicas e culturais. Esta visão ampliada da organização da realidade coloca em xeque a eficiência da "guerra de movimento" 5 ", se em contextos anteriores foi adequada, na realidade em questão não é capaz de cumprir seu papel. Este posicionamento impulsiona o pensador a buscar uma estratégia capaz de atacar os efeitos produzidos por todas as dimensões presente na organização da realidade. Como resposta a esta necessidade define como estratégia a "guerra de posições" 6 ".

Tem-se claro então que na perspectiva gramsciana a revolução do proletariado esta para além do embate na dimensão da produção material, sendo necessário o embate no campo ideológico e cultural. Desta forma a revolução do proletariado passa obrigatoriamente pela exigência de "[...] elaborar um novo tipo humano, conforme ao novo tipo de trabalho e produção [...]" (GRAMSCI, 1980, p.382). Este homem tem de ter uma postura crítica e criativa frente o mundo do qual faz parte, sendo capaz de perceber-se como sujeito ativo capaz de escolhas e decisões.

${ }^{5}$ Guerra de movimento - Método revolucionário proposto por Marx e Engels que defende a tomada do poder por meio da força. Esta lógica fundamentou as ações de Gramsci e dos demais socialistas italianos para enfrentar as difíceis condições vividas pelos trabalhadores durante a Primeira Guerra Mundial. O "chão de fábrica" era considerado o centro do poder da burguesia, motivo pelo qual a ocupação das fábricas foi definida como estratégia de combate. Para realizar tal feito os trabalhadores se organizaram por meio de comissões internas de fábrica que tomaram corpo passando a ser representativa de todos os trabalhadores de uma determinada empresa, passou a se ter então o "trabalhador coletivo". Esta estratégia possibilitou a ocupação de várias empresas na Itália, entre os anos de 1919 e 1920, período que foi denominado de "Biênio Vermelho". Porém o avanço do proletariado logo foi sufocado por uma rearticulação da burguesia italiana.

${ }^{6}$ Guerra de posições - Método revolucionário que tem como estratégia atacar os efeitos produzidos por todas as dimensões presentes na organização da realidade. Embate no campo ideológico e cultural. Faz-se necessário esclarecer que a proposição de estratégias diferentes não caracteriza uma divergência e oposição onde Marx e Engels estariam de um lado e Gramsci de outro. Esta e outras divergências são frutos dos diferentes momentos históricos vivenciados por eles. A realidade concreta analisada por Gramsci possuía novos contornos em virtude da consolidação da hegemonia capitalista. Porém os pressupostos fundantes do marxismo são observados por Gramsci em suas elaborações. O que se pode afirmar é que sendo a sociedade uma constituição histórica e, portanto dinâmica Gramsci a partir dos pressupostos do marxismo originário da continuidade ao trabalho de Marx. Desta forma a passagem da estratégia de "guerra de movimento" para a estratégia de "guerra de posições" acontece por uma exigência da realidade concreta em questão. 
A elaboração deste novo "tipo humano" defendido por Gramsci tem como condição indispensável uma relação dialética entre práticas sociais e conhecimento, tendo em vista que em sua percepção entre conhecimento e política existe uma relação determinante para a consolidação da hegemonia. Nesta perspectiva a epistemologia passa a ser elemento central na constituição das relações de poder, desempenhando papel de destaque na estratégia contra-hegemônica gramsciana, posto que por meio do conhecimento torna-se possível compreender qual é a concepção de mundo que sustenta a vida dos diferentes grupos sociais e como esta concepção é elaborada e difundida, tornando-se uma concepção hegemônica. Este papel político da epistemologia é condição prévia para a efetivação de seu compromisso maior: elaborar ações que promovam o rompimento desta visão de mundo fragmentada e acrítica das classes subalternas objetivando a construção de uma reforma intelectual e moral com vista a tornar a classe subalterna uma "classe para si".

Na concepção de Gramsci o conhecimento passa a ser arma fundamental para garantir o êxito da contra-hegemonia, porém para que isso se efetive faz-se necessário perceber as dimensões: científica, política e pedagógica que tem de assumir o conhecimento, isto é o conhecimento deve alavancar novas ações que venham a contribuir para modificar o amoldamento das relações sociais do bloco histórico vigente. Pode-se dizer então que a epistemologia estabelece uma relação de unidade dialética com a política, o que permite compreender a indissociável relação entre conhecimento e realidade concreta. $\mathrm{O}$ conhecimento necessita ser construído a partir da realidade e sobre tudo com o propósito de nela efetivar modificações que venham a qualificar as classes subalternas.

Esta proposição de Gramsci pode ser explicitamente percebida quando este afirma que:

Criar uma nova cultura não significa apenas fazer individualmente descobertas "originais", significa também, e sobretudo, difundir criticamente verdades já descobertas, "socializá-las" por assim dizer, transformá-las, portanto, em base de ações vitais, em elementos de coordenação e de ordem intelectual e moral. O fato de que uma multidão de homens seja conduzida a pensar coerentemente e de maneira unitária a realidade presente é um fato "filosófico" bem mais importante e "original" do que a descoberta por parte de um" gênio filosófico", de uma nova verdade que permaneça como patrimônio de pequenos grupos intelectuais. (GRAMSCI, 1995, p.13-14). 
A epistemologia gramsciana é fundamentalmente propositiva. Não se limita a compreensão e formulação de conceitos que explicitem quem é o homem, como a sociedade se estrutura, qual o papel desempenhado pela natureza no contexto socioeconômico. Tem como intencionalidade propor possibilidades de transformações para o homem, para a sociedade e para a forma como a natureza é percebida no contexto socioeconômico, buscando o romper com a passividade que envolve as classes subalternas.

Diante do exposto é notório o caráter decisivo que as diferentes visões de mundo assumem frente às proposições dos indivíduos e, consequentemente, nas ações destes em sua vida cotidiana, sendo assim um fator determinante dos contornos da constituição econômica e social. Partindo desta premissa Gramsci ressalta a importância que o senso comum e a filosofia, enquanto concepções de mundo desempenham em sua estratégia de transformação social. A relação dialética que se estabelece entre estas concepções acaba por modular e sedimentar os modelos civilizatórios. Isto porque, a despeito do entendimento da existência de uma multiplicidade de visões de mundo, acontece a formação de grupos que pela similaridade de suas visões pensam e agem a partir de mesmas premissas, estabelecendo se neste grupo um senso comum que faz consolidar uma unidade ideológica. Assim na perspectiva gramsciana o senso comum adquire uma conotação mais complexa que a habitualmente utilizada, vinculando-se diretamente à teoria do conhecimento. Este passa a assumir um papel ético-político tendo em vista que garante uma padronização no modo de pensar e agir dos grupos sociais. Esta padronização proporciona um modo passivo de ser e estar no mundo, conduzindo suas ações a partir de concepções que lhe foram forjadas pelo ambiente exterior, assumindo como suas as concepções que lhes foram impostas. Tal engendramento resulta na naturalização das condições produzidas pelas determinações inerentes ao modelo civilizatório, onde as condições de submissão e expropriação encontram-se presentes.

Torna-se importante ressaltar que a estratégia de superação do senso comum não busca negar a concepção de mundo existente, e sim analisá-la, criticá-la, retirando o que há de coerente, transformando-a, em uma concepção mais homogênea. Trata-se de trabalhar o bom senso- núcleo sadio do senso comum -, procurando desenvolvê-lo e transformá-lo em consciência de classe, construindo assimuma visão de mundo que seja elaborada a partir de seus interesses. 
Este é o núcleo sadio do senso comum, o que poderia ser chamado de bom senso, merecendo ser desenvolvido e transformado em algo unitário e coerente. Tornam-se evidentes, assim, as razões que fazem impossível a separação entre a chamada filosofia "científica" e a filosofia "vulgar" e popular, que é apenas um conjunto desagregado de idéias e de opiniões. (GRAMSCI, 1995, p.16).

Gramsci registra que o núcleo de bom senso, que existe no interior do senso comum, deve ser trabalhado para levar a consciência a uma maior coerência e homogeneidade, e isso acontece através da filosofia da práxis. A filosofia da práxis é vista como uma teoria da organização e da ação política, a qual se apresenta, inicialmente, em uma atitude polêmica e crítica, como superação da maneira de pensar precedente e do pensamento concreto existente (ou mundo intelectual existente) (GRAMSCI, 1995). Nesta perspectiva, o autor não concebe manter os "simplórios" na sua filosofia primitiva do senso comum. Ao contrário, tem como objetivo conduzi-los a uma concepção de vida superior. Para tal, acredita ser necessária a realização de um contrato entre os intelectuais e os "simplórios", a fim de dar vida a um bloco intelectualmoral, que torne politicamente possível o progresso intelectual de massa.

Por meio da filosofia da práxis, as classes subalternas realizam um processo de tomada de consciência, chegando a uma elaboração superior da própria consciência do real. Esta autoconsciência é ponto fundamental para o processo de transformação social, visto que o homem ativo, de massa, atua de forma prática, porém não tem consciência teórica de sua ação, podendo, inclusive, sua consciência estar historicamente em contradição com seu agir:

É quase possível dizer que ele tem duas consciências teóricas (ou uma consciência contraditória): uma, implícita na sua ação, e que realmente o une a todos os seus colaboradores na transformação prática da realidade; e outra, superficialmente explícita ou verbal, que ele herdou do passado e acolheu sem crítica. Todavia, esta concepção "verbal" não é inconseqüente: ela liga a um grupo social determinado, influi sobre a conduta moral, sobre a direção da vontade, de uma maneira mais ou menos intensa, que pode, inclusive, atingir um ponto no qual a contraditoriedade da consciência não permita nenhuma ação, nenhuma escolha e produza um estado de passividade moral e política. (GRAMSCI, 1995, p.20-21).

A consciência de fazer parte de uma ou outra força hegemônica é o ponto de partida para a autoconsciência, na qual teoria e prática se unem, a fim de alcançar uma 
concepção de mundo coerente e unitária. Porém é importante ressaltar que a construção desta concepção de mundo não é um movimento espontâneo, isso porque a dinâmica que envolve sua sedimentação é cuidadosamente arranjada pelo bloco hegemônico, a fim de boicotar possíveis tentativas de superação. Para tanto os intelectuais organicamente vinculados a classe subalterna desempenham papel fundamental. Estes devem proporcionar condições para que o proletariado possa construir seus valores, desejos e comportamentos a partir da sua realidade concreta, tanto econômica como social, tendo presente as suas necessidades e interesses. Aos intelectuais cabe a tarefa de levar às classes subalternas a filosofia da práxis, através de uma reflexão que obrigatoriamente se dá no núcleo de bom senso, a partir da prática cotidiana das massas e de sua experiência na luta política, isto é, o desenvolvimento da autoconsciência, visto que:

\begin{abstract}
Autoconsciência crítica significa, histórica e politicamente, criação de uma elite de intelectuais: uma massa humana não se "distingue" e não se torna independente "por si", sem organizar-se (em sentido lato); e não existe organização sem intelectuais, isto é, sem organizadores e dirigentes, sem que o aspecto teórico da ligação teoria-prática se distinga concretamente em um estrato de pessoas "especializadas" na elaboração conceitual e filosófica. (GRAMSCI, 1995, p.21).
\end{abstract}

Sendo assim, os intelectuais difundem a concepção de mundo revolucionária entre as classes subalternas, trabalhando para elevar a consciência dispersa e fragmentária das massas sob os dirigentes e organizadores das classes subalternas a fim de que esses alcancem a hegemonia do proletariado.

Segundo Gramsci,

[...] o intelectual tem por função homogeneizar a concepção do mundo da classe à qual está organicamente ligado, isto é, positivamente, de fazer corresponder esta concepção à função objetiva desta classe numa situação historicamente determinada ou, negativamente, de a tornar autônoma, expulsando desta concepção tudo o que lhe é estranho. $\mathrm{O}$ intelectual não é, pois, o reflexo da classe social: ele desempenha um papel positivo para tornar mais homogênea a concepção naturalmente heteróclita desta classe. (PIOTTE apud MOCHCOVICH, 1992, p.18).

Este papel dos intelectuais está alicerçado em um trabalho epistemológico, onde se torna necessário ter no conhecimento um aliado que permita ao indivíduo ter uma percepção de si a partir do papel que realmente desempenha como membro de uma determinada classe. Assim será capaz de construir criticamente uma concepção de 
mundo que seja coerente com suas necessidades e interesses, ao invés de captar para si uma visão de outrem que lhe aprisiona em um mundo de ilusões.

Nessa estratégia contra-hegemônica, o conhecimento assume papel ético-político e a educação torna-se de vital importância, pois é espaço onde podem ser desenvolvidas novas percepções de mundo capazes de possibilitar a construção de um novo modelo civilizatório. No entanto, é oportuno frisar que não se trata de qualquer projeto de educação. A educação pode ter seu papel ético-político comprometido com a manutenção de um determinado bloco histórico, como pode, também, estar a serviço da transformação social, destaca-se assim a não neutralidade da educação.

\section{CONSIDERAÇÕES FINAIS}

As reflexões explicitadas nesse artigo permitem uma compreensão mais ampla e mais profunda da crise socioambiental, deixando claro, a necessidade de percebê-la para além das questões do ambiente físico e biológico. Compreender a vinculação dessa crise com o modo de produção capitalista aponta para a urgência da superação do modelo civilizatório vigente. Desse modo, torna-se premente refletir sobre o problema ambiental de forma articulada com a totalidade das dimensões da sociedade, pois a não articulação resulta em uma visão dualista de mundo, onde a luta pela preservação da natureza ocorre de forma desarticulada da luta por justiça e igualdade social, quando na verdade tem de ser percebidas em íntima relação.

Nessa perspectiva a Educação Ambiental Transformadora torna-se de extrema relevância, uma vez que em sintonia com o materialismo histórico dialético, investe em uma concepção de educação não doutrinária, mas que esteja a serviço da transformação social. Compreender o papel ético-político da educação é ponto fundamental para a construção de um sujeito crítico e criativo engajado na construção de um novo modelo civilizatório. 
ABSTRACT: The social environmental crisis reach hazard proportions and it should be thought beyond the physical and biological environment. This is set like a problem that includes the economic, social and politic dimensions in their interrelations, being conditioned to the current civilizing pattern: the capitalism. As theoretical basis, the Marxian thinking and the Transformative Environmental Education assumptions, this article aims to problem the role of the Education to overcome the social environmental crisis to build the Education and especially of a pedagogical practice that is in harmony with the thinking for contributing with the counter-hegemonic process. On this perspective, is problem the Gramscian thinking, specially the politic-ethical role of Education to overcome the social environmental crisis.

KEYWORDS: Social environmental crisis. Transformative environmental education.Marxian thinking.

\section{REFERÊNCIAS}

BACKES, M. Notas a tradução. In: MARX, K.; ENGELS, F. A ideologia alemã: crítica da novíssima filosofia alemã em seus representantes Feuebach, B. Bauer e Stirner, e do socialismo alemão em seus diferentes profetas, 1845-1846. Rio de Janeiro: Civilização Brasileira, 2007. p.9-17.

GRAMSCI, A. Concepção dialética da história. 10.ed. Rio de Janeiro: Civilização Brasileira, 1995.

Maquiavel, a política e o Estado moderno. Tradução de Luiz Mário Gazzaneo. 4.ed. Rio de Janeiro: Civilização Brasileira, 1980.

LAYRARGUES, P. P. Para que a Educação ambiental encontre a educação. In: LOUREIRO, C. F. B. (Org.). Trajetória e fundamentos da educação ambiental. 2.ed. São Paulo: Cortez, 2006. p.11-18.

LEFF, H. Ecologia, capital e cultura: racionalidade ambiental, democracia participativa e desenvolvimento sustentável. Blumenau: EDIFURB, 2000.

LOUREIRO, C. F. B. Trajetória e fundamentos da educação ambiental. 2.ed. São Paulo: Cortez, 2006.

MARX, K.; ENGELS, F. A ideologia alemã: crítica da novíssima filosofia alemã em seus representantes Feuebach, B. Bauer e Stirner, e do socialismo alemão em seus diferentes profetas, 1845-1846. Rio de Janeiro: Civilização Brasileira, 2007.

MOCHCOVITCH, L. G. Gramsci e a escola. São Paulo: Ática,1992. 